\title{
Multi item inventory model with demand dependent on unit cost and varying lead time under fuzzy unit production cost; a Karush Kuhn Tucker conditions approach
}

\author{
P. Vasanthi, C. V. Seshaiah \\ Department of Mathematics, Sri Ramakrishna Engineering College, Coimbatore-22, TN, India
}

Email address:

vasdev1066@gmail.com (P. Vasanthi)

\section{To cite this article:}

P. Vasanthi, C. V. Seshaiah. Multi Item Inventory Model With Demand Dependent On Unit Cost And Varying Lead Time Under Fuzzy Unit Production Cost; A Karush Kuhn Tucker Conditions Approach. Applied and Computational Mathematics.

Vol. 2, No. 6, 2013, pp. 124-126. doi: 10.11648/j.acm.20130206.12

\begin{abstract}
A multi item inventory model with demand dependent on unit price and leading time with limited storage space and set up cost is considered in this paper. The varying production and leading time crashing costs are considered to be continuous functions of unit price and leading time respectively. The model is solved using Karush Kuhn Tucker conditions approach with optimal order quantity, unit price and leading time as decision variables. In most of the real world situations, the cost parameters, the objective functions and constraints of the decision makers are imprecise in nature. In this paper the unit cost has been imposed in fuzzy environment. An optimal total cost is obtained which is illustrated with numerical example for a single item.
\end{abstract}

Keywords: Inventory, Demand Dependent on Unit Cost, Lead Time, KKT Conditions, Fuzzy Unit Cost

\section{Introduction}

Inventory control plays an important role as the total investment in inventories if various kinds is quite substantial. The constrained multi-item inventory model had been treated by many researchers. Maloney and Klein (7) discussed constrained multi-item inventory systems: an implicit approach using algorithms method. A demand dependent unit cost has been treated by some researchers in the problem of EOQ model. Abou-El-Ata and Kotb (1) developed a crisp inventory model under two restrictions. The pioneer work began by Cheng (4), who studied an EOQ model with demand dependent unit cost of single item using geometric programming approach. Ben-Daya and Abdul Raouf(3) discussed the problem of inventory model involving lead time as a decision variable. Teng and Yang (11) examined deterministic inventory lot size model with time varying demand and cost under generalized holding costs. Other related studies were written by Juneau and Coates (5), Jung and Clein (6) and Mandal et al (8).

Zadeh (12) first gave the concept of fuzzy set theory. Later on Bellman and Zadeh (2) used the fuzzy set theory to the decision making problem. Nirmal Kumar Mandal and Maiti (9) solved fuzzy inventory model with three constraints using geometric programming approach. Recently Ravi Shankar (10) used Genetic algorithm to solve a fuzzy non linear optimization problem.

In this paper a multi item inventory model with demand dependent on unit price is considered and solved using Karush Kuhn Tucker conditions. Also the leading time crashing cost is considered as a function of lead time and solved. The unit production cost, lot size and lead time are the decision variables. The unit cost is treated as a fuzzy variable in order to get the optimum total cost. The model is illustrated with numerical example for a single item.

\section{Notations and Assumptions}

To construct the model of this problem, we define the following notations.

$n=$ number of different items carried in inventory

$W=$ Floor (or) shelf-space available

$B=$ Limitation on total set up cost

For $i^{\text {th }}$ item: $(i=1,2, \ldots n)$

$D i=$ Annual demand rate (function of unit cost)

$Q i=$ Production (order) quantity batch (decision variable) 
$\mathrm{Si}=$ Ordering cost

$H i=$ Unit holding (inventory carrying) cost per item

$p_{i}=$ unit purchase (production) cost (decision variable)

$w_{i}=$ storage space per item

$T C(\mathrm{p}, Q, \mathrm{~L})=$ Average annual total cost

$\mathrm{SS}=\mathrm{k} \sigma \sqrt{L_{i}}=$ Safety stock

$\mathrm{Li}=$ Leading rate time (decision variable)

The following basic assumptions about the model are made.

(i) Demand rate is related to unit price as $D_{i}=A_{i} p_{i}^{-\beta_{i}}$ where $\mathrm{Ai}>0$ and $\beta_{\mathrm{i}}\left(0<\beta_{\mathrm{i}}<1\right)$ are constants and real numbers related to provide the best fit of the estimated price function.

(ii) Time horizon is finite

(iii) No shortages are allowed.

(iv) Lead time crashing cost is related to the lead time by a function of the form $R\left(L_{i}\right)=a L_{i}^{-b}, \mathrm{i}=$ $1,2, \ldots \mathrm{n}, \mathrm{a}>0, \quad 0<\mathrm{b} \leq 0.5$, where $\mathrm{a}$ and $\mathrm{b}$ are real constants.

(v) Objective is to minimize the annual relevant total cost.

\section{Mathematical Formulation}

The annual relevant total cost [Sum of production, order, inventory carrying and lead time crashing costs] which, according to the basic assumptions of the EOQ model is

$$
T C\left(p_{i}, Q_{i}, L_{i}\right) \boxminus \sum_{i=1}^{n}\left[p_{i} D_{i}+\frac{S_{i} D_{i}}{Q_{i}}+\left(\frac{Q_{i}}{2}+k \sigma \sqrt{L_{i}}\right) H_{i}+\frac{D_{i}}{Q_{i}} R\left(L_{i}\right)\right](1)
$$

Substituting $\mathrm{D}_{\mathrm{i}}$ and $\mathrm{R}\left(\mathrm{L}_{\mathrm{i}}\right)$ in (1) yields,

$$
T C\left(p_{i}, Q_{i}, L_{i}\right) \boxminus \sum_{i=1}^{n}\left[A_{i} p_{i}^{1-\beta_{i}}+\frac{S_{i} A_{i} p_{i}^{-\beta_{i}}}{Q_{i}}+\left(\frac{Q_{i}}{2}+k \sigma \sqrt{L_{i}}\right) H_{i}+\frac{A_{i} p_{i}^{-\beta_{i}}}{Q_{i}} a L_{i}^{-b}\right]
$$

There are some restrictions on available resources in inventory problems that cannot be ignored to derive the optimal total cost.

(i) There is a limitation on the available warehouse floor space where the items are to be stored

(i.e) $\sum_{i=1}^{n} w_{i} Q_{i} \leq W$

(ii) There is a limitation on the total set up cost.

(i.e) $\sum_{i=1}^{n} \frac{D_{i}}{Q_{i}} S_{i} \leq B$

(i.e) $\sum_{i=1}^{n} A_{i} p_{i}^{-\beta_{i}} S_{i} Q_{i}^{-1} \leq B$

The problem is to find the unit production cost, lot size and lead time so as to minimize the total average cost function (2) subject to the total space and set up cost restrictions. It may be written as

$$
\operatorname{MinTC}\left(p_{i}, Q_{i}, L_{i}\right) \boxminus \sum_{i=1}^{n}\left[A_{i} p_{i}^{1-\beta_{i}}+\frac{S_{i} A_{i} p_{i}^{-\beta_{i}}}{Q_{i}}+\left(\frac{Q_{i}}{2}+k \sigma \sqrt{L_{i}}\right) H_{i}+\frac{A_{i} p_{i}^{-\beta_{i}}}{Q_{i}} a L_{i}^{-b}\right]
$$

subject to the inequality constraints

$$
\begin{gathered}
\sum_{i=1}^{n} w_{i} Q_{i} \leq W \\
\sum_{i=1}^{n} A_{i} p_{i}^{-\beta_{i}} S_{i} Q_{i}^{-1} \leq B
\end{gathered}
$$

\section{Fuzzification of Cost Parameter}

In this paper the unit production cost $\mathrm{p}_{\mathrm{i}}$ is defined under fuzzy environment. The membership function for the fuzzy variable $\mathrm{p}_{\mathrm{i}}$ is defined as follows.

$$
\mu_{p_{i}}(X)=\left\{\begin{array}{c}
1, p_{i} \leq L_{L_{i}} \\
\frac{U_{L_{i}}-p_{i}}{U_{L_{i}}-L_{L_{i}}}, L_{L_{i}} \leq p_{i} \leq U_{L_{i}} \\
0, p_{i} \geq U_{L_{i}}
\end{array}\right\}
$$

Here $\mathrm{U}_{\mathrm{Li}}$ and $\mathrm{L}_{\mathrm{Li}}$ are upper limit and lower limit of $\mathrm{p}_{\mathrm{i}}$ respectively.

\section{Numerical Example}

We shall compute the decision variables (optimal production cost $\mathrm{p}$, optimal order quantity $\mathrm{Q}$, and optimal lead time L) whose values are to be determined to minimize the annual relevant total cost.

The parameters of the model are shown in Table 1

Assume the standard deviation $\sigma=6$ unit/year and $\mathrm{K}=2$.

The values of the decision variables are calculated for some different values of $\beta$, $a$ and $b$.

Table 1. Input values

\begin{tabular}{ccccccc}
\hline $\mathbf{n}$ & $\mathbf{S i}$ & $\mathbf{A i}$ & $\mathbf{H i}$ & $\mathbf{w}_{\mathbf{i}}$ & $\mathbf{W}$ & $\mathbf{B}$ \\
\hline 1 & $\$ 100$ & 100 & $\$ 1$ & $2 \mathrm{sq} \mathrm{ft}$ & $100 \mathrm{sq} \mathrm{ft}$ & $\$ 200$ \\
\hline
\end{tabular}

$\$ 19 \leq$ pi $\leq \$ 39$

Table 2. Optimal solution table for varying $\beta$ and $a=1, b=0.1$

\begin{tabular}{ccccccc}
\hline $\boldsymbol{\beta}$ & $\mathbf{p}_{\mathbf{i}}$ & $\mathbf{Q i}$ & $\mathbf{L i}$ & $\mathbf{M i n} \mathbf{T C}$ & $\mathbf{D i}$ & $\boldsymbol{\mu}_{\mathbf{p i}}$ \\
\hline 0.88 & 19.36 & 38.880 & .000067 & 181.654 & 7.370 & 0.982 \\
0.89 & 23.744 & 34.983 & .000055 & 176.773 & 5.967 & 0.763 \\
0.90 & 29.650 & 31.185 & .000046 & 167.267 & 4.733 & 0.468 \\
0.91 & 38.186 & 27.453 & .000037 & 166.201 & 3.634 & 0.041 \\
\hline
\end{tabular}


Table 3. Optimal solution table for varying $a$ and $\beta=0.88$ and $b=0.1$

\begin{tabular}{ccccccc}
\hline $\mathbf{a}$ & $\mathbf{p}_{\mathbf{i}}$ & $\mathbf{Q i}$ & $\mathbf{L i}$ & $\mathbf{M i n} \mathbf{T C}$ & $\mathbf{D i}$ & $\boldsymbol{\mu}_{\mathbf{p i}}$ \\
\hline 1 & 19.360 & 38.880 & .000067 & 181.654 & 7.370 & 0.982 \\
2 & 19.844 & 39.030 & .000200 & 182.655 & 7.213 & 0.958 \\
5 & 20.766 & 39.243 & .000860 & 183.328 & 6.927 & 0.861 \\
8 & 38.186 & 39.330 & .000180 & 184.344 & 6.697 & 0.871 \\
\hline
\end{tabular}

Table 4. Optimal solution for varying $b$ and $\beta=0.88$ and $a=1$.

\begin{tabular}{ccccccc}
\hline $\mathbf{b}$ & $\mathbf{p}_{\mathbf{i}}$ & $\mathbf{Q i}$ & $\mathbf{L i}$ & $\mathbf{M i n} \mathbf{T C}$ & $\mathbf{D i}$ & $\boldsymbol{\mu}_{\mathbf{p i}}$ \\
\hline 0.1 & 19.360 & 38.880 & .000067 & 181.654 & 7.370 & 0.982 \\
0.2 & 19.779 & 39.014 & .000680 & 182.226 & 7.233 & 0.961 \\
0.3 & 20.037 & 39.076 & .002800 & 182.830 & 7.151 & 0.948 \\
0.4 & 20.276 & 39.131 & .007400 & 183.466 & 7.077 & 0.936 \\
\hline
\end{tabular}

From the table 2 it follows that as the parameter $\beta$ value increases the unit production cost also increases while that of the values of the lot size, lead time and demand rate decreases and hence the corresponding total annual cost also decreases. Though the total cost decreases, the optimum minimum $\mathrm{TC}=\$ 181.654$, since the membership function is maximum when $\beta=0.88$. Hence the optimum values are

$\mathrm{p}_{\mathrm{i}}=\$ 19.36, \mathrm{Qi}=38.88, \mathrm{Li}=0.000067$ and $\mathrm{Min} \mathrm{TC}=$ $\$ 181.654$

From the table 3 and 4 it follows that as the parameter a and $b$ increases, the decision variables namely the production cost, the lot size and the lead time also increases and hence the total cost also increases, while the demand rate decreases. The maximum membership function corresponds to $\mathrm{a}=1$ and $\mathrm{b}=0.1$. Hence the optimal values are

$\mathrm{p}_{\mathrm{i}}=\$ 19.36, \mathrm{Qi}=38.88, \mathrm{Li}=0.000067$ and $\mathrm{Min} \mathrm{TC}=$ $\$ 181.654$

The solution table reveals that the decision variables production cost $p_{i}$, lot size $Q_{i}$ changes rapidly as $\beta$ changes while the decision variable $\mathrm{L}_{\mathrm{i}}$ change rapidly when the values of the parameters $a$ and $b$ changes.

\section{Conclusion}

This paper is devoted to study the multi-item inventory model that consider the unit production cost, lot size and lead time as three decision variables. These variables pi, Qi and $\mathrm{Li}$ are evaluated and the minimum total cost is deduced for single item. The minimum total cost is found at the least values of $a$ and $b$. This paper can be extended by varying the restrictions like investment, lot size etc. Also it can be extended for more than one item.

\section{References}

[1] M.O.Abou-El-Ata, and K.A.M.Kotb, Multi-Item EOQ Inventory Model with Varying Holding cost under two restrictions; A Geometric Programming Approach, Planning and Control, 6(1997), 608-611.

[2] R.E.Bellman and L.A.Zadeh,Decision - Making in a Fuzzy Environment Management Science, 17(4), (1970), B141B164.

[3] M.Ben-Daya and Raouf, Inventory Models involving Lead time as a Decision Variable, Journal of the Operational Research Society, Vol.45 (5), 1994, 579-582.

[4] T.C.E.Cheng, An Economic Order Quantity Model with Demand dependent Unit cost, European Journal of Operations Research, 40(1989), 252-256.

[5] J.Juneau and E.R.Coates, An Economic Order Quantity Model for Time Varying Demand, Journal of Modern Engineering, 2(2001).

[6] H.Jung and C.M.Klein, Optimal Inventory policies under decreasing cost functions via Geometric Programming, European Journal of Operations Research, 132(2001), 628642.

[7] B.M. Maloney and C.M.Kleing, Constrained Multi-item Inventory Systems: An Implicit Approach, Computers Operations Research, 6,(1993), 639-649.

[8] N.K.Mandal, T.K.Roy and M.Maiti, Inventory Model of Deteriorated items with a Constraint: A Geometric Programming Approach, European Journal of Operations Research, 173(2006), 199-210.

[9] Nirmal Kumar Mandal, T.K.Roy, M.Maiti, Multi-Objective Fuzzy Inventory Model with Three Constraints; A Geometric Programming Approach, Fuzzy Sets \& Systems, 150 (2005), 87-106.

[10] N.Ravi Shankar, G.Ananda Rao, J.Madhu Latha and V.Sireesha, Solving a Fuzzy Nonlinear Optimization Problem by Genetic Algorithm, International Journal of Contemporary Mathematical Sciences, Vol.5, No.16,(2010) 791-803.

[11] J.T.Teng and H.L Yang, Deterministic Inventory lot Size Models with Time Varying Demand and Cost under Generalized Holding costs, Information and Management Sciences, Vol. 18 (2), 2007, 113-125.

[12] L.A.Zadeh, Fuzzy Sets, Inform and Control, 1965, 338-353 